\title{
THE NECESSITY OF MOBILE TRAIN RADIO COMMUNICATION IN INDIA
}

\author{
Joyjit Chatterjee ${ }^{1}$

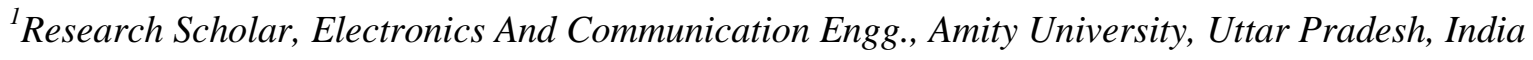

\begin{abstract}
Presently, India has the dubious distinction of recording an exponential number of train accidents as compared to its other developed counterparts. Though, no accident is completely avoidable, what can be done is to develop a certain technologically advanced machinery which can scale down the prospects of such accidents and expedite Disaster Management in case of any mishap. This would help to curtail the damage to life and property. The "Mobile Train Radio Communication (MTRC) "system is a dynamic and technologically avant-garde system based on the "Global System for Mobile Communication-Railways (GSM-R)" technology and it can play an intrinsic role in abbreviating train accidents by aiding effective communication.

With the passage of time, India has shown its technological capability to the world, be it through the successful launch of the "Mangalyaan" in the very first attempt, the invention of various machines and electronic gadgets by the Engineers and Scientists across the country, the development of India as a nuclear power and so on. As Dr. D. Swaminadhan said in his speech, "Science and technology have been an integral part of Indian civilization and culture over the past several millennia". India has the best of resources and technical minds available, through which it can move ahead of its other developed counterparts. As life is very precious, a major requirement of the present is to switch over to the "MTRC" system at the earliest. The railway accidents over the past decade cannot be neglected and the unfortunate events cannot be entirely reasoned as an event occurring out of chance. Trains are merely machines running on railway tracks and they cannot think of how to avoid accidents on their own. As B.F. Skinner rightly said "The real problem is not whether machines think, but whether men do". It is up to the human beings to design and use an efficient system which can help the train driver and the station master to know about the possibility of any untoward hazard beforehand by developing effective communication between the concerned officials.
\end{abstract}

Key Words: Train Communication, MTRC system , GSM-R Technology, Train Accident

\section{INTRODUCTION}

Since its inception in 1853, Indian Railways have progressed a long way. Presently, India has the third largest railway network in the world, covering a total length of around 65,000 Kilometers. [1] With the passage of time, Railways have become a commonly used medium for long distance transport in India. More and more passengers are using Railways as a means of travel. Millions of tones of goods are now being transported by trains. Indian Railways transport 7651 billion passengers and over 921 million tones of goods annually.

As the world is getting technologically advanced, more complications have set in regarding safety and security of passengers. The report of the High Level Safety Review Committee of 2012 estimates that almost 15,000 number of persons gets killed every year in train accidents. Apart from this, security in trains is also a major concern. Considering all these necessities, the need of the hour is to develop an effective and a technologically advanced communication system in the Indian Railways.

The Mobile Train Radio Communication (MTRC) system [2] seems to be the right answer to these concerns. MTRC uses the "Global System for Mobile CommunicationsRailway (GSM-R)" technology [3] to facilitate an instant and constant interaction with the train crew with the Control Centre and Station Master. It ensures safety of passengers by providing effective communication between Driver and Control Room. The MTRC system can be used to warn the drivers beforehand of the running trains as well as the concerned officials. In case of any security problem, concerned staff can immediately intimate the concerned security establishment. If any accident takes place, the MTRC system will facilitate better post-disaster management. In the present day, Railways need not just effective voice transmission, but also have the capability to analyze all the technical data to arrive at the correct decision to be taken on the spot.

In India, as per Action Plan of Vision 2020 and safety concerns highlighted by the High Level Safety Review Committee report, a beginning has been made to put MTRC into use in the railways. The MTRC project is being implemented by the Indian Railways Project Management Unit (IRPMU), and it is expected that this technology will help to improve the Railway communication in India manifold and make Railways a safer and better mode of transport for the common man. 


\section{NATIONAL AND INTERNATIONAL STATUS}

\section{Current Scenario: Signaling and}

\section{Telecommunication in the Indian Railways network}

Effective signaling is necessary for the proper functioning of railways. The Signaling and Telecommunication Department of the Indian Railways plays as integral role to ensure glitch-free signaling operations. The Corporate Safety Plan laid in 2003 opens up the avenues for the Signaling \& Telecommunication body by striving for technological up-gradations and maintenance of the existing railways machinery.

In 2008, the Performance Audit conducted under the Special Railway Safety Fund reviewed the progress in meeting the aims which were raised in the Corporate Safety Plan initiated in 2003. The audit revealed that no zone, out of the 16 zones, was able to fulfill completely, all the objectives under the Corporate Safety Plan for the Signaling and Telecommunication plans like Mobile Train Radio Communication, Panel Interlocking, Solid State Interlocking, Track Circuiting etc. [4] It indicated that the funds could be better utilized through effective planning and implementation of new technologies. It paved a way for the development of efficient machinery to curtail the incidence of train accidents in India.

With the increase in rail traffic in India, the spate of Railway Accidents has also increased tremendously. Many reports, including the one given by the High Level Safety Committee reveal the rise in train accidents over the past decade. Most of these accidents have occurred due to failure, complete or partial, or malfunctioning of the railways Communications System. The graph give below makes it clear that most of the Train Accidents from 2009 to 2014 have occurred due to inefficient machinery and human failure. Many accidents have occurred at the unmanned railway crossings and these could have been avoided by the presence of effective Signaling and Communication machinery.

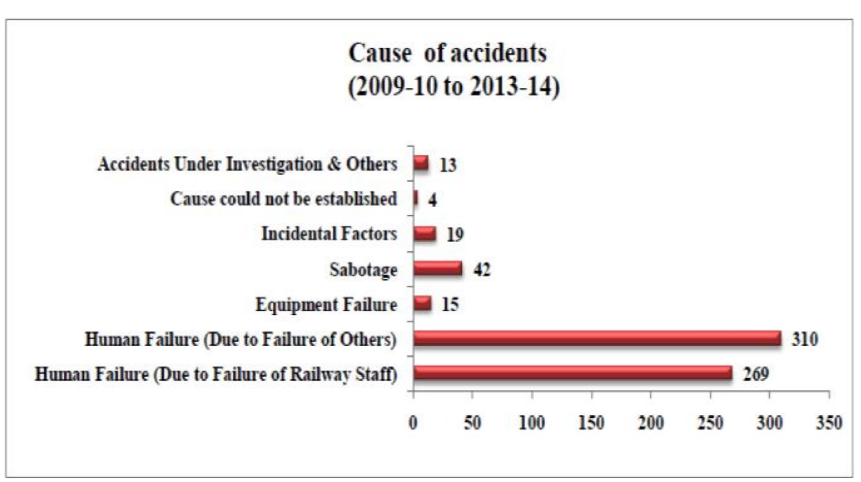

Figure 1-“Indian Train Accidents Statistics" [5]
As per an article in the Hindustan Times entitled "The killer trains of India", the number of people who were killed in train accidents in the last ten years, is significantly higher than the combined number of Passenger Deaths in the UK, US and Canada. This article reveals the fact that though India has a vast railway network requiring more effort for effective management, the record of countries with similar large networks of railways is much better. There has been less number of casualties in these countries due to train accidents. This calls for implementation of better technology and up-gradation of existing Communication System at the earliest.

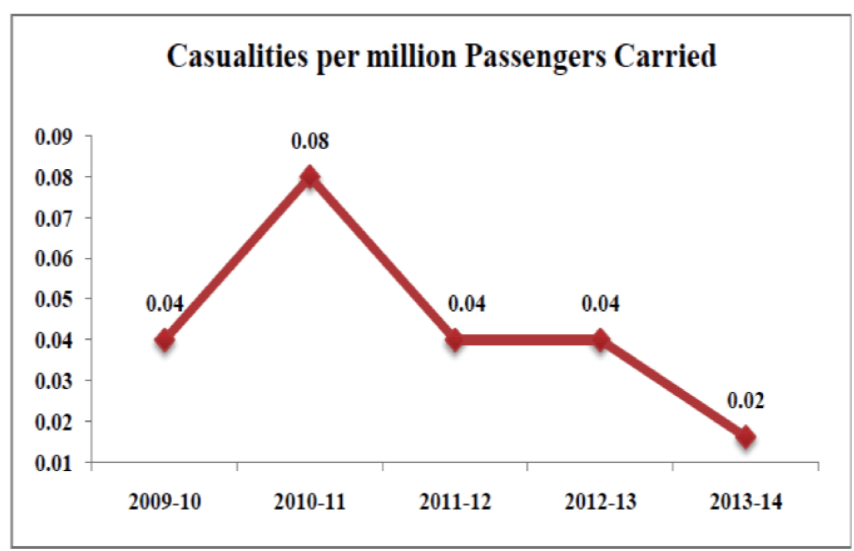

Figure 2:"Statistics of Indian Railways Accidents"' [6]

To our respite, implementation of effective technology and action plans by the Indian Railways has lead to a dip in the Train Accidents over the years. The casualties per million passengers carried have fallen from 0.04 in 2009-10 to 0.02 in 2013-14. This is, in fact, an achievement for the Indian Railways.

The map given below illustrates the vast network of the Indian Railways, spreading its wings over the 16 zones. It shows the reason for a layman to believe that India has the third largest Railway Network of world. Many visitors come from across the globe to have an experience of travelling in the Indian trains. The zest of travelling in trains in Indiawith the hawkers selling some quick snacks in the local trains, the delicious food being served to the passengers in the trains, the beautiful and captivating landscape of the routes through which the trains pass, and the comfort provided to the tourists in the Rajdhani, Shatabdi and Duronto trains is worth appreciation. No doubt, Railways is the most preferred mode of long distance transport for the people travelling in India. 


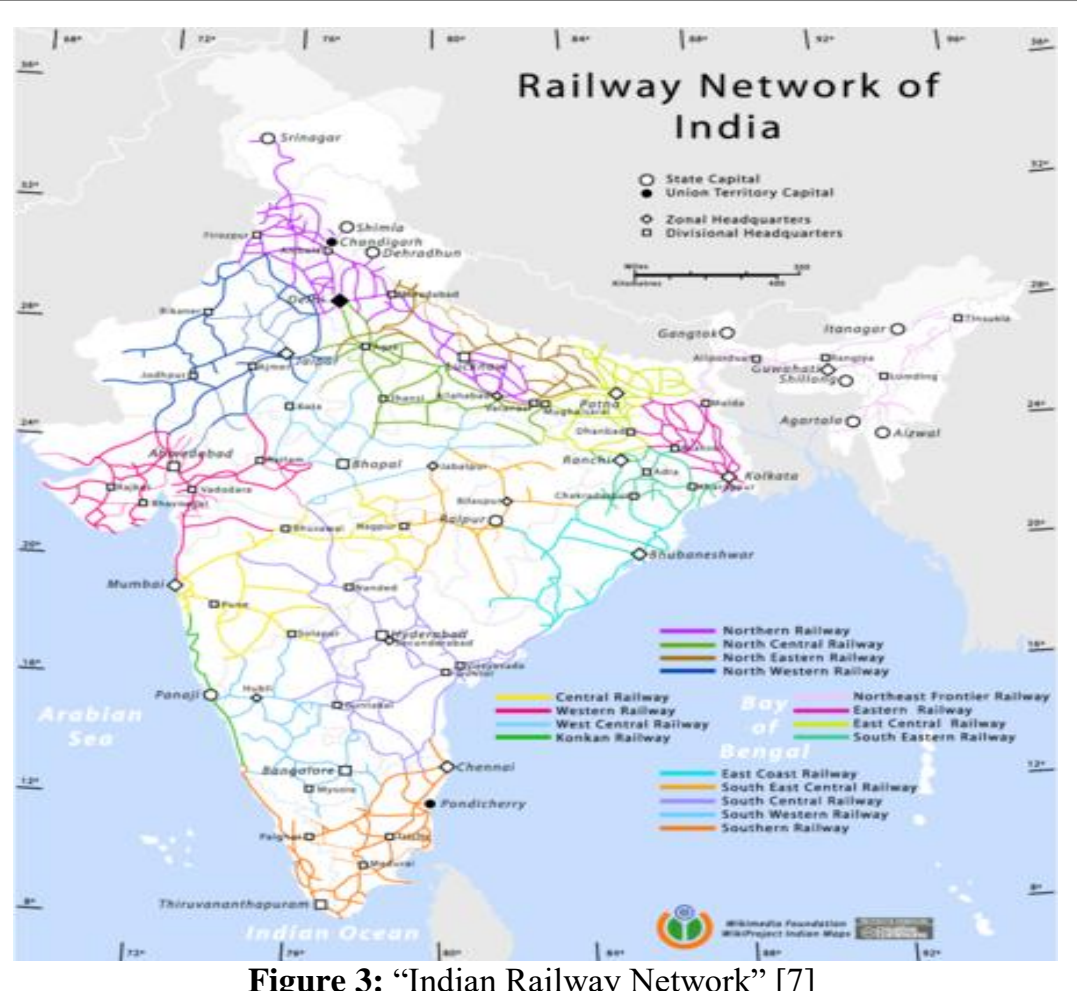

Figure 3: "Indian Railway Network" [7]

Though, these reasons are more than enough for us to feel great about travelling in Indian Trains, the displeasing statistics about the Train Accidents in India arise as a cause of concern for the Indian Railways. In India, there is a culture of "Atithi Devo Bhava" meaning Guest is like God. People who travel in trains are the guests and their safety is of utmost concern and importance to the Railway Authorities. To meet the expectations of millions of passengers who travel by trains daily, it is high time to implement newer plans etc. and make betterment in the present technology. It is time for a complete switchover from Analog Communication to Digital Communication. And what can be a better option in the present times than to switch to MTRC in all sectors and zones of the Indian Railways.

The "Indian Railways Project Management Unit (IRPMU)" is doing an excellent job in implementing the various strategies for this switchover and various other bodies of the Indian Railways, including the Telecom Directorate, Ministry Of Railways, Indian Railways have undertaken the tedious task of going digital through MTRC in the vast railways network of India.

An effort was made in the 1980 s to switch over to the MTRC system. Out of the 16 zones of the Indian Railways, South Eastern Railways and Central Railways incorporated the change. Though, the system was fine enough to fulfill the needs of that time, the bulky mobile handsets and machinery for charging made it unsuitable for use by the drivers and guards. The machinery was simply based on Radio Communication by propagation of Radio Waves, was prone to malfunctioning and not reliable.

As a consequence of these drawbacks, the Indian Railways decided to move ahead and introduced Mobile Train Radio Communication based on GSM-R technology. It all started with the introduction of the full duplex communication based system in the Nagpur-Itarsi section, MughalsaraiHowrah, and the Delhi-Mughalsarai section. It marked the beginning of the MTRC revolution in India. The system lacked the essence of the MTRC in real sense as it could facilitate communication only between the driver and the control room or the guard and the control room, lacking the ability to aid direct communication between the concerned staff. The "Gaisal Train Disaster", which occurred on $2^{\text {nd }}$ August, 1999 due to the collision between the Avadh Assam Express from Dibrugarh and the Bramhaputra Mail from New Delhi, leading to more than 280 deaths and leaving over 320 people injured forced the Indian Railways to expedite the changeover to MTRC system. Finally in 2005, the MTRC project was sanctioned and Nokia Siemens Network given the work of implementing MTRC based on GSM-R technology in India. The Nokia Siemens Network implemented the country's first GSM-R based MTRC system in May,2008 for the North Central Zone of the Indian Railways. It dramatically changed the way the drivers of the running trains and the guards communicate with the control room.

As on $31^{\text {st }}$ March,2013, only around 2,200 Route Kilometers (RKM's) of the 64,980 RKM's of the railway network have been covered by the GSM-R based MTRC system. Around Rs 205.94 Crores of expenditure has been incurred and over Rs 1000 Crores is required to cover the whole of Indian Railways' 20,000 RKMs of A, B and C railway routes.

It is the need of the hour to switch to MTRC at the earliest to curtail Train Accidents and safe journey for the passengers. As of now, the work is going on, and it is expected that if plans are properly implemented and funds fully utilized, in a few years from now, the vast network of Indian Railways will be fully equipped with the modern day GSM-R based MTRC system for Railway Communications. 


\section{Mobile Train Radio Communication to facilitate Railway passengers}
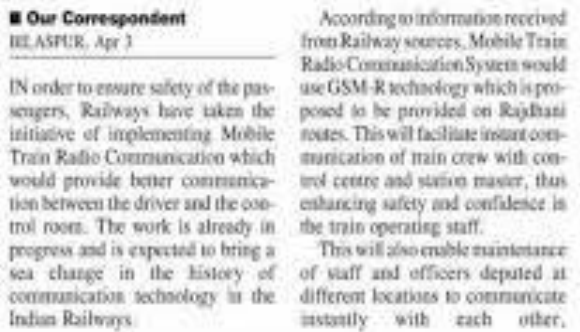

thereby enhancing the sysxent efficiency matifold

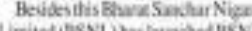
Limiantios

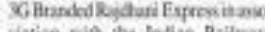

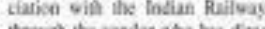
the ger the vasor who has dices

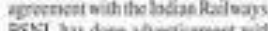

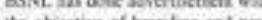
the objective of branding ind pro maine of 36 grodests nid valu

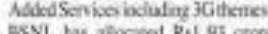
BSNL has abocased Rsi.95 croo:

Figure 4:"MTRC to facilitate Railway passengers" [8]

Following the footsteps of the Indian Railways, the other railway bodies have also begun to implement the MTRC system for rail transport in India. The Metro Railway is also being covered by the GSM-R based MTRC system. India first Metro Railway network (Metro Railway, Kolkata) has initiated the work of implement the MTRC system to Replace the non reliable and outdated "Very High Frequency (VHF)" based train Radio Communication system. The "Delhi Metro Rail Corporation (DMRC)" has also moved ahead to implement the GSM-R based MTRC system. These projects which have been undertaken in the various railway sections in India are more than enough to say, that an excellent beginning has been made to switch over to the GSM-R based MTRC system and very soon, the Indian trains will exhibit a highly efficient, reliable, consistent and glitch-free Mobile Train Communication machinery and it will drastically reduce the incidence of train accidents in India.

\section{A BIRD'S EYE VIEW OF THE MTRC} SYSTEM IN SINGAPORE AND SAN

\section{FRANCISCO}

The study on the scope of MTRC system in India will not be complete until we realize the advancements made internationally in the implementation of MTRC system across the world. Internationally, the MTRC system is being widely implemented in many countries for a range of railways applications and uses, the main purpose of implementation being improvement of passenger safety. Moreover, the speeds of trains are very high and thus, trains are more prone to accidents.

Also, there is an increasing trend of driverless trains around the world. These automatic trains move at very high speeds, undoubtedly are better than ordinary trains due to the diligence, versatility, accuracy and minimal human interference. But, these trains require a highly advanced and efficient communication system to prevent malfunctioning and any glitches, which can pose a risk to the passengers. Due to this reason, the MTRC system is being implemented in countries across the world. The map given below shows the various MTRC train projects in the world, including the ones on which work is still going on. In this study, we take a bird's eye view into the MTRC system in Singapore and San Francisco.

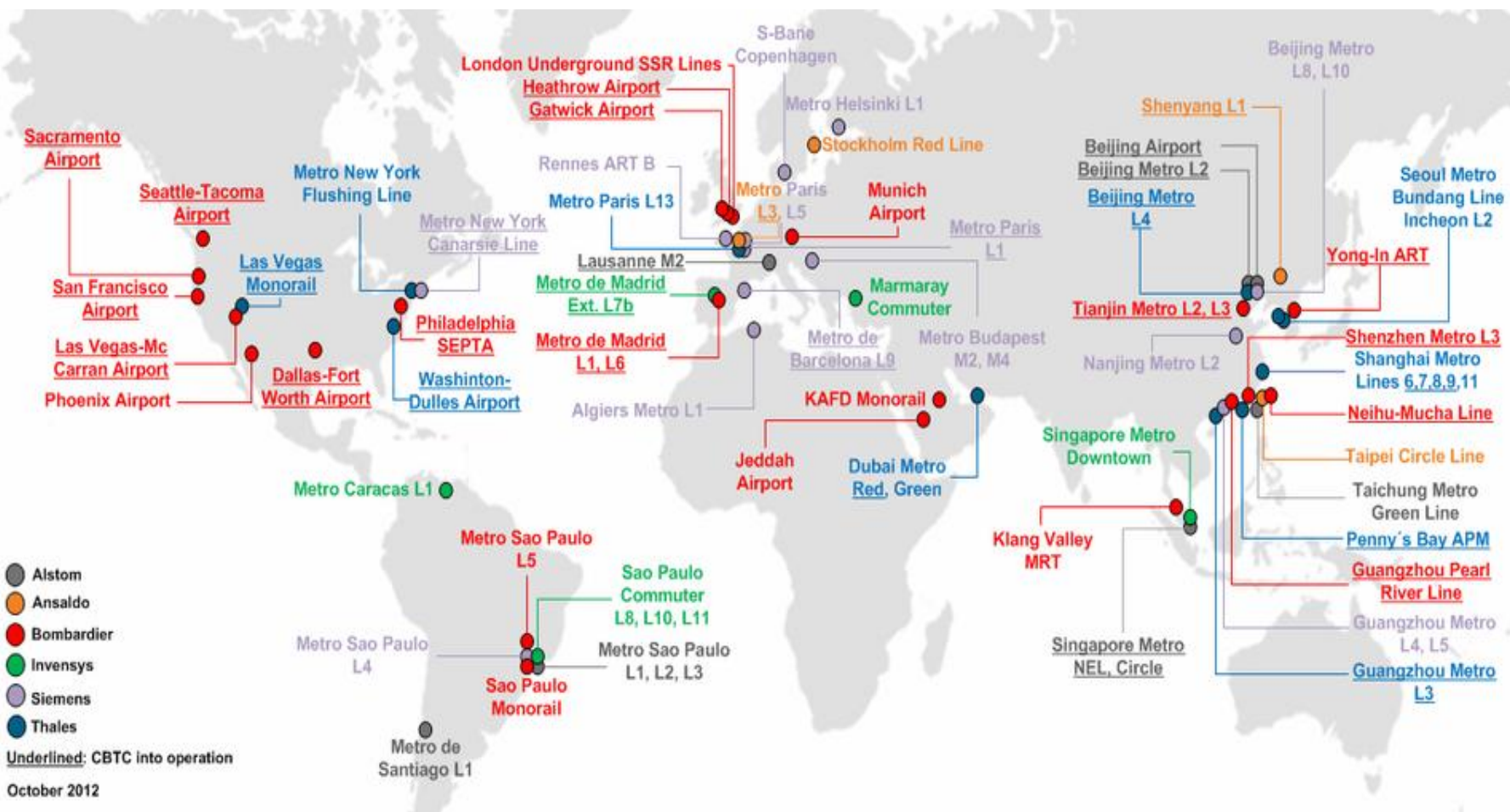

Figure 5:"MTRC system across the world" [9] 


\section{MTRC SYSTEM IN SINGAPORE}

In 2003, the world's first Radio Communication Based Train Control system was implemented in Singapore by "Alstom", a French MNC which has implemented MTRC system in various developed counties. The project was implemented across 2 Metro Lines, the first being the 16 station North-East line and the other being the 29 station circle line. The North East line in Singapore a highly advanced and fully automatic underground driverless train line, a first of its kind in the world. The completion of this project in 2003 made Singapore the first country in the world to have a fully automatic metro based on the MTRC model for communication in the world's longest and highest capacity metro trains. The MTRC system supplied is very advanced and fulfills the high standards laid down by the Singapore's "Land Transit Authority (LTA)" for passenger safety and quality of service.

The Map given below shows the metro railway network of Singapore. The network is very well planned and consists of an efficient MTRC system.

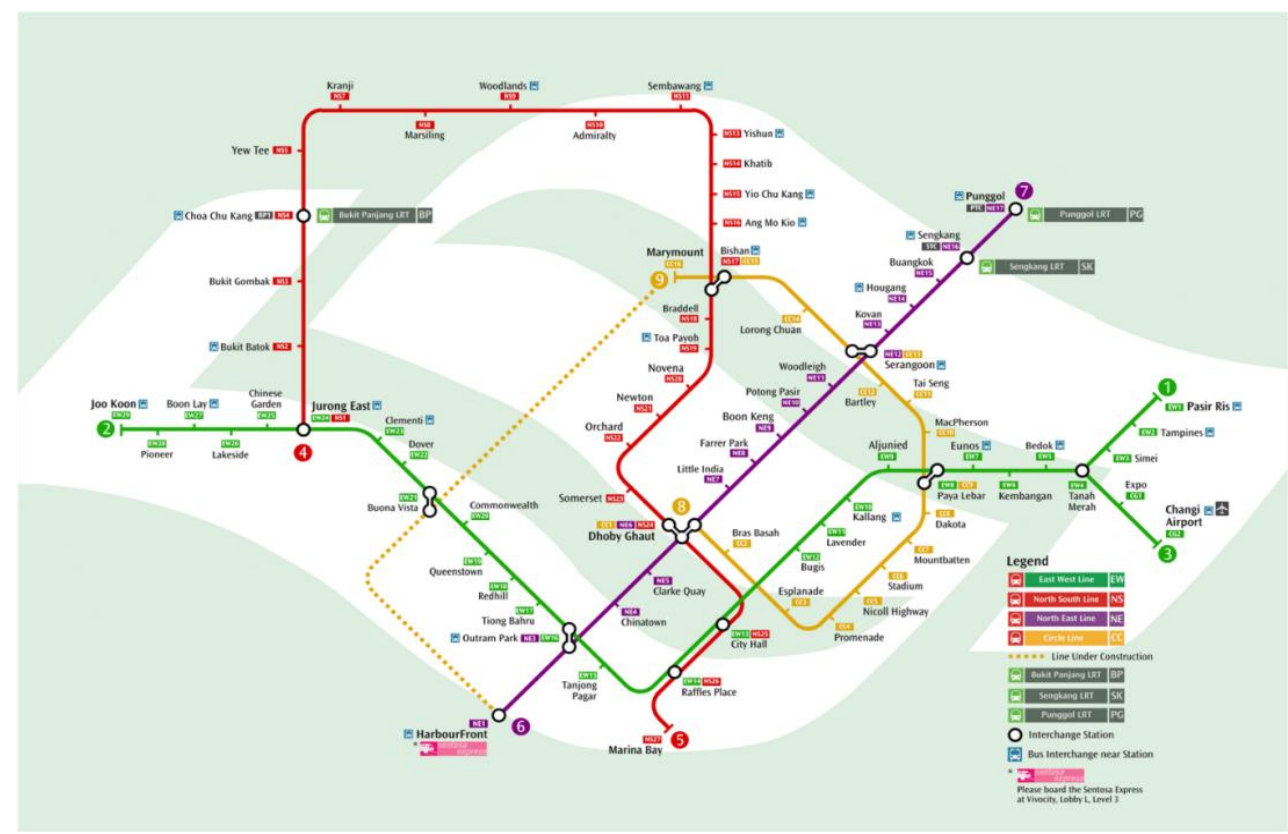

Figure 6:"MTRC system in Singapore" [10]

\section{MTRC SYSTEM IN SAN FRANCISCO'S AIR}

\section{TRAIN}

Bombardier Transportation implemented a fully automatic train at the San Francisco Airport in 2003. Better known as the Air Train, the driverless train connects all of the San Francisco Airport's parking areas, terminals and the Bay Area Rapid Transit (BART) station. The map given below illustrates the network across which the Air Train operates.

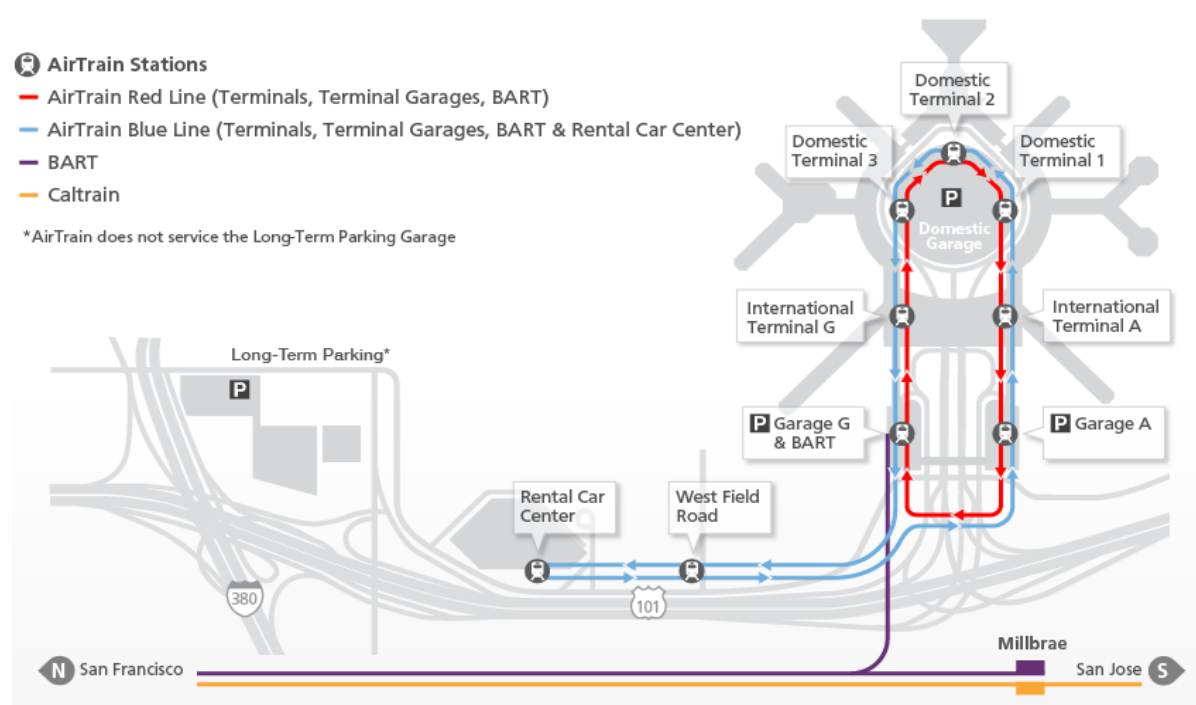

Figure 7 [11] 
The Air Train operates 24 hours a day across 2 lines- the Red Line and the Blue Line, and makes it very convenient for the passengers to move across various terminals and avenues of the San Francisco International Airport. The train covers 9 stations and has a daily passenger movement of around 2,30,000 people. The total track length is around 9.8 $\mathrm{Km}$. the Air Train is an excellent example to show that the MTRC system facilitates the transportation of passengers through the "Automatic People Mover (APM)" based on the technically advanced concept of fully automatic and driverless trains. Presently, there are a total of 39 APM's which carry people across the Air Train network and the train makes effective use of MTRC system to facilitate effective communication between the driverless train and the control room.

\section{A GLANCE INTO THE GSM-R}

\section{TECHNOLOGY}

The "Global System For Mobile Communications-Railway (GSM-R)" is an international standard for wireless communication pertaining to railways. With the changing times, railway operators of the major developing and developed nations have come together to define a standard which is universally acceptable for railway communication. This resulted in the layout of specifications by the "European Integrated Railway Enhanced Network (EIRENE)" which were validated by "Mobile Radio for Railway Networks in Europe (MORANE)". The GSM-R technology is designed in line with the "EIRENE-MORANE Functional Requirement Specification (FPS)" which provides for effective communication for very high train speeds, even up to $500 \mathrm{Km} / \mathrm{Hr}$ without appreciable data loss and attenuation. The GSM-R technology thus provides for a highly reliable and glitch-free railway communication system. Though the GSM-R system is not much isolated from the GSM technology which is widely used for regular Public Mobile Communications, it has a frequency band most suitable for the railways. It also has many advanced features which regular Public Mobile Networks based on GSM do not have.

There are two types of specifications laid down by "EIRAINE":-

- "Functional Requirement Specification (FRS)"- It defines a range of high functional level requirements for railway communication.

- "System Requirement Specification (SRS)"- It defines technical solutions to various functional requirements for railway communication.

\section{FREQUENCY BAND IN GSM-R}

The GSM-R Radio Link makes effective use of "Frequency Division Multiple Access (FDMA)" and "Time Division Multiple Access (TDMA)". Unlike regular Public Mobile Networks using GSM, the Mobile Train Radio Communication using the "Global System For Mobile Communications-Railway (GSM-R)" needs a specific frequency band pertaining to railway applications and uses.
Moreover, this is needed to ensure minimum glitch and passenger safety. While in GSM, one needs to see the two dimensional aspect of communication, trains move in effectively one dimensional manner. As the technology involves a network of linear GSM, Directional Antennas can be used to improve the propagation characteristics. For Indian Railways, the Telecom Directorate has recommended $900 \mathrm{MHz}$ frequency band for downlink and uplink signals respectively. They are essentially 935-960 MHz and 890$915 \mathrm{MHz}$

\section{NUMBERING PLAN}

The numbers defined by the Numbering Plan laid out by the "EIRAINE" are used for communication pertaining to specific sections of railways through a unique "Mobile Station International Subscriber Directory Number (MSISDN)". The following table describes the various digits to be dialed on the handsets by the concerned staff of the train crew for different applications and uses. These have been described in a "System Requirements Specifications (SRS)" document of the "EIRAINE".

\begin{tabular}{|c|c|}
\hline Digit & Use \\
\hline 1 & "Reserved for short codes" \\
\hline 2 & "Train Function Number" \\
\hline 3 & "Engine Function Number" \\
\hline 4 & "Coach Number" \\
\hline 50 & "Group calls" \\
\hline 51 & "Broadcast calls" \\
\hline $\begin{array}{c}52- \\
55\end{array}$ & "Reserved for international use" \\
\hline $\begin{array}{c}56- \\
57\end{array}$ & "Reserved for national use" \\
\hline 58 & "Reserved for system use" \\
\hline 59 & "Reserved for system use" \\
\hline 6 & "Maintenance and shunting team members" \\
\hline 7 & "Train controllers" \\
\hline 8 & "Mobile Subscriber Number" \\
\hline 9 & "Reserved for breakout codes and national use" \\
\hline 0 & $\begin{array}{l}\text { "Reserved for access to the public or other GSM-R } \\
\text { networks" }\end{array}$ \\
\hline
\end{tabular}

Figure 8: "EIRAINE Numbering Plan" [12]

As per a report of the "Research Designs and Standards Organization (RDSO)", India, Functional Number is assigned as follows:-

$$
\underline{\mathrm{A}} \quad \underline{\mathrm{B}} \quad \underline{\mathrm{C}} \quad \underline{\mathrm{D}} \quad \underline{\mathrm{E}}
$$

Here, A-E are the various numbers with different specifications:

$>$ A denotes the call type. It is different for different requirements of the call.

$>$ B denotes the day on which the train is running. Example: It will be 2 for a train running on Tuesday. 
$>\mathrm{C}$ denotes the train number.

$>$ D denotes the train type. It is 0 for a schedule train, 1 for link train and 2 for special train.

$>$ E denotes the user to whom the call is to be made.

It is 01 for Driver of the train and 80 for the Guard of the train.

The users can register themselves as a Guard or a Driver of any train from their mobiles by dialing the "Railway Access Code (RAC)" following the Functional Numbers as per above specifications.

\section{SYSTEM ARCHITECTURE}

The GSM-R system mainly consists of:

* "Base Station Sub System (BSS)"

* "Mobile Station (MS)"

* "Operating Sub System (OSS)"

* "Network and Switching Sub System (NSS)"

* "Cab Radio"

* "Dispatcher"

* "Power Supply arrangement"

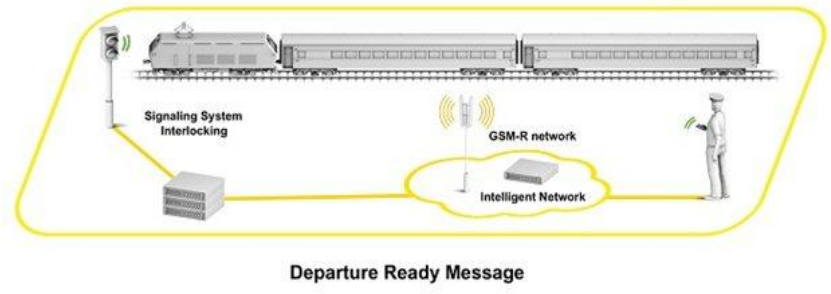

Figure 10: Communication Based Train Control [13]

\section{FEATURES OF MODERN "MOBILE TRAIN}

\section{RADIO COMMUNICATION (MTRC)” \\ SYSTEMS}

The present day "Mobile Train Radio Communication (MTRC)" systems exhibit many advanced features which enhance the overall system of railways operations and ensure that the optimum passenger safety conditions are met. These include, but are not limited to the following important features:-

$>$ The modern trains having "Mobile Train Radio Communication (MTRC)" system simultaneously calculate and communicate their running status through radio communication to the drivers and the control rooms.

$>$ The communicated status includes many important details about the running trains like the accurate position of trains, their speed, braking distance and the direction in which they travel in terms of their position coordinates.

$>$ The MTRC system also allows the wayside equipments to highlight such points on the railway track which may be called as nodes, which should not be crossed by other trains moving on the same path. As per the Manual on Uniform Traffic Control Devices, 2009 given by the "US Department of Transportation, Federal Highway Administration", Wayside equipment includes the switches, signal systems, control devices etc. for railway transit operations housed within one or more than one enclosures located on the railway tracks.

$>$ It greatly reduces the "Safety Braking Distance" between two trains by continuous and accurate train location and speed details which allows for simple calculation through the kinematics equations of motion. The appropriate programming is done in the microprocessors and "Integrated Circuits (IC's)" embedded in the hardware of the MTRC systems which does the calculation of ambient "Safety Braking Distance".

$>$ The MTRC system provides for easy switchover and upgradation to driverless trains as it is based on a highly advanced communication technology.

$>$ The MTRC system, by calculating the most efficient train speed for minimum energy loss incorporates train coasting (Due to which the train runs down the track because of its own gravity, without making use of other energy forms like steam or electric power. This helps save energy.

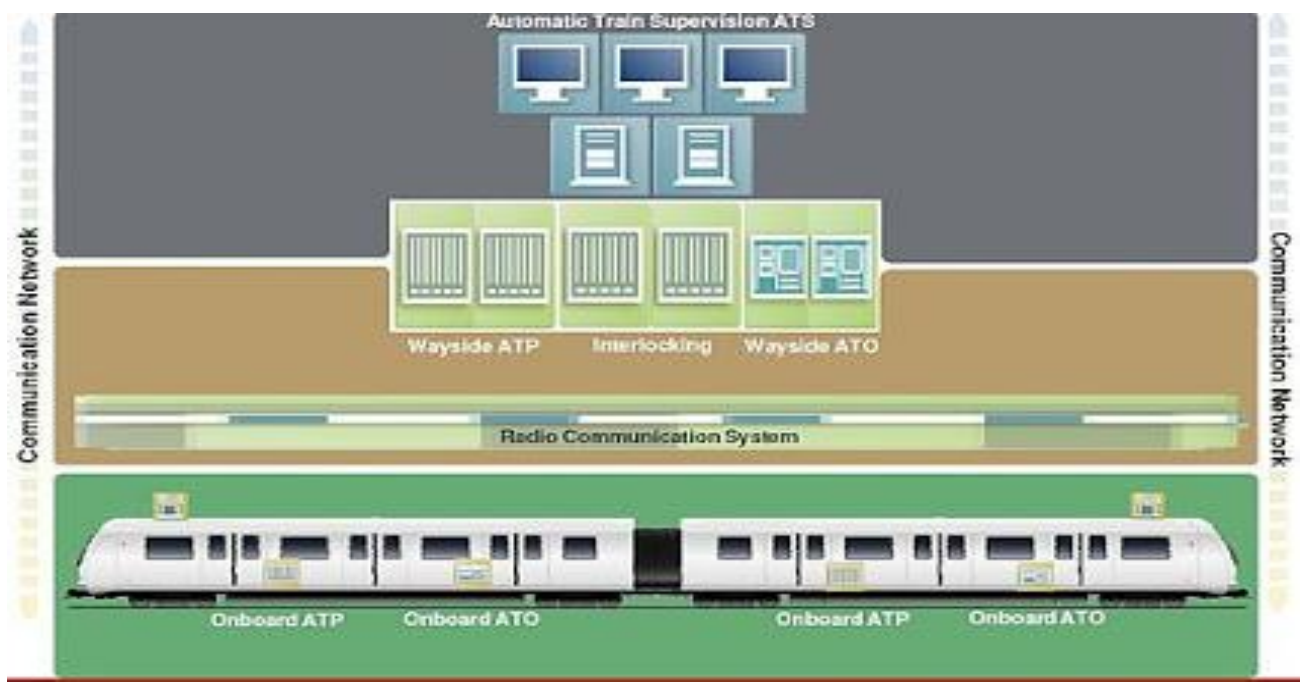

Figure 11:" Automatic Train Supervision" [14] 


\section{RISKS IN USING THE "MOBILE TRAIN}

\section{RADIO COMMUNICATION (MTRC)" SYSTEM}

Even though the "Mobile Train Radio Communication (MTRC)" system has many advanced features to ensure maximum efficiency in railways operations and passenger safety, like any other technology, it also has some drawbacks which need to be taken into consideration when designing or using the system for railways communication:-

- The major risk is that if the communication between any of the trains fails or is hampered, then the MTRC system might fail, wholly or partially, endangering the safety of passengers.

- $\quad$ As the MTRC system uses Radio Communication for all applications, there can be communication failures due to weak signal strengths, attenuation, electromagnetic (EM) interference or glitch in the functioning of the hardware.

- As the system makes use of wireless communication, it can be subjected to unethical hacking, again putting the passenger safety into question.

- $\quad$ Due to malfunctioning of equipment, there can be unexpected and unwanted application of emergency brakes, which can cause train accidents.

\section{CONCLUSION}

It would not be wrong to conclude that the MTRC systemwill have an important role to play in the field of rail transport in the near future as India is entering into a phase where Bullet Trains are shortly to be introduced starting from small sectors which will have high speed of more than over $600 \mathrm{Km} / \mathrm{Hr}$. Such high speed trains have a high risk of derailment and other hazards like failure of signals, communication system, and human failure. To successfully launch the system of Bullet Trains and to ensure its safe operation, the MTRC system, undoubtedly, is not just essential, but a must.

\section{Bullet out of Delhi}

COMING SOON Air-conditioned rail network that will drastically reduce travel time

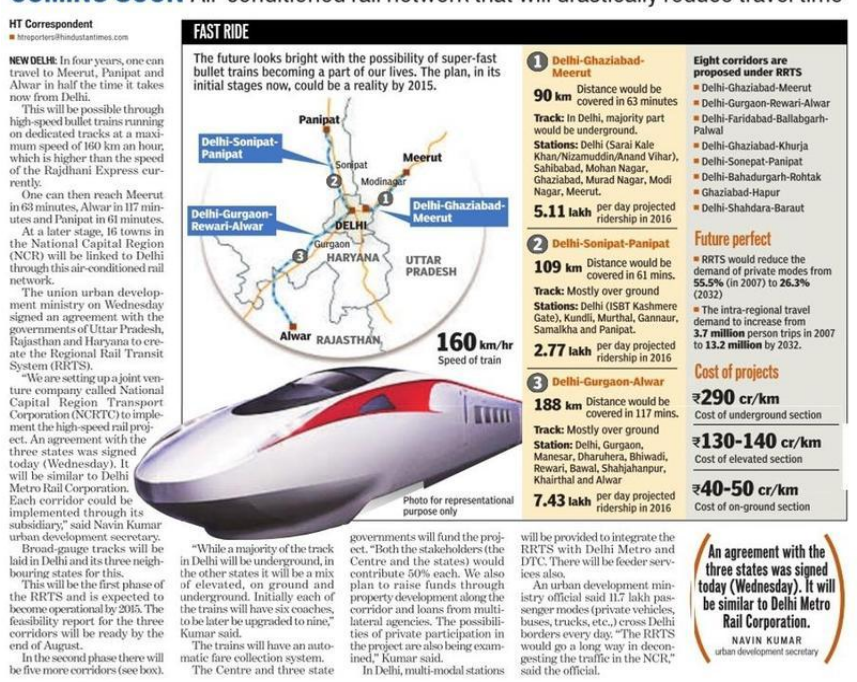

Figure 12:[16]
Trains with fully automated system i.e. in layman's word, driverless trains are not a dream of the distant future in India as shortly, as per various media reports; Delhi will get its first driverless and fully automated Metro Train which is expected to be fully operational by 2016. In this case, "Mobile Train Radio Communication" has a great role to play by culminating the efficiency of communication between the train's communication machinery and the railway control room through the use of "Global System for Mobile Communications-Railway" technology. The MTRC system will provide complete details about the train and its running status to the railway officials concerned like information about the train's speed, its current direction of movement based on "Global Positioning System (GPS) ", time of train's arrival and departure, the current passenger strength on the train, the track details on which the train is running and many more.

For effective implementation of the "Mobile Train Radio Communication system" in India, Govt. of India has a major and important role to play. A budget of around Rs 1000 Crores has been worked out for installation and running of the system in major routes of Railway including those areas which are prone to accidents and other hazards. Another expenditure of Rs 1000 Crores will be required to cover the entire Railway network comprising about 65,000 RKMs. So far, only about Rs 206 Crores has been pumped by Govt. of India for making expenditure on preliminary activities in connection with implementation of MTRC system. Thus, Govt. Of India has to fund this infrastructural venture, so that the MTRC system is operational at least in major routes by 2020 . The Govt. Of India will also have to think about our limited financial resources and the expenditure which cannot be avoided like budget on Defence and Railways for maintenance and up-gradation of the existing facilities and networks. But, it seems that the Government will evolve other fund raising measures like issue of long term Railway Bonds etc, so that India does not lack behind the other developed countries in running of the MTRC system in India. This will not only help immensely in increasing safety measures for the public and property of India, but will also help in generating employment to technocrats and other workforce for operation of the MTRC system. The last, but not the least consideration should be uniform Govt. policies and strategies, if India has to achieve the target of Action Plan 2020.

As Elbert Hubbard rightly said," One machine can do the work of fifty ordinary men. No machine can do the work of one extraordinary man". The power of imagination and creativity in the designing of the MTRC system is immense and India can develop the best MTRC system in the world. Engineers have a major role to play in designing, installation and running of the system. The foremost measure would be to engage professionals along with fund and equipments for carrying out an effective R\&D with major focus on Indian terrains, weather and vast network. More importantly, the Electronics and Communication Engineers have a tedious task ahead, to ensure that the communication system facilitates the purpose of the Indian Railways at the minimum cost with maximum efficiency. 
Finally, I would conclude the research work on this subject with high expectations of increase in employment, reduction in train accidents etc, growth of Human Capital and putting India in the world map of developed nations with respect to MTRC system. India is among the countries with best technical and scientific minds and it is sure that India will one day lead and lend its technical services for installation of the system in other developing countries.

\section{REFERENCES}

[1] "Railways in India", Wikipedia the Free Encyclopedia; https://en.wikipedia.org/?title=Indian_Railways

[2] "MTRC system", International Union of Railways ; www.uic.org

[3] "GSM-R technology", Wikipedia; (https://en.wikipedia.org/wiki/GSM-R)

[4] Avishek Banerjee, IIT Kharagpur, "Railway Accidents in India: By chance or by design? “;http://cse.iitkgp.ac.in/resgrp/cnerg/Files/avishek_baner jee.pdf

[5] "Indian Train Accidents statistics"; www.factly.in

[6] Srinad Jha, Hindustan Times "Killer Trains of India"; (Jul 30,2012)

[7] "Indian Railway network"; Wikipedia the Free Encyclopedia (en.wikipedia.org)

[8] "Mobile Train Radio Communication to facilitate Railway passengers"; TOI, 04/03/13

[9] "MTRC system across the world" ; en.wikipedia.org

[10] "MTRC system in Singapore" ; http://bernardteozy.blogspot.in/

[11] "San Francisco's Air Train" ; http://www.flysfo.com/maps/ground-transport

[12] "EIRAINE SRS Specifications"; www.uic.org

[13] "Communication Based Train Control"; Wikipedia the free encyclopedia

[14] (http://en.wikipedia.org/wiki/Communicationsbased_train_control )

[15] "Automatic Train Supervision"; Wikipedia the Free Encyclopedia ( en.wikipedia.org)

[16] "Bullet out of Delhi"; Hindustan Times

\section{BIOGRAPHY:}

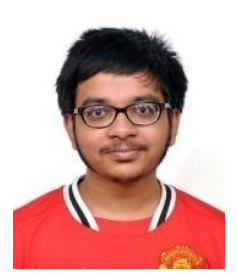

Mr. Joyjit Chatterjee is a Research Scholar of Electronics and Communications Engineering. Mr. Chatterjee has an inborn interest to simplify the complex issues for the common man by describing the appropriate use of Science and

Technology. He has been awarded the Amul Vidya Bhushan Award for Academic Excellence and a Letter of Appreciation from the Ministry Of Human Resource Development. 